\title{
Beyond modality and hedging: A dialogic view of the language of intersubjective stance
}

\author{
P. R. R. WHITE
}

Abstract

This article offers a framework for analysing the linguistic resources of intersubjective positioning, meanings which have elsewhere been treated under such headings as modality, polarity, evidentiality, hedging, concession, intensification, attribution and consequentiality. Drawing inspiration from Bakhtin/Vološinov's dialogic perspective, it proposes that this lexicogrammatically diverse grouping can be brought together on discourse semantic grounds, namely that they all provide the means for speakers/ writers to take a stance towards the various points-of-view or social positionings being referenced by the text and thereby to position themselves with respect to the other social subjects who hold those positions. The paper offers a typology of these resources, with categorizations attending to differences in the way the textual voice engages with the alternative voices andlor pointsof-view being referenced or activated by the text. It argues, for example, that these resources can be broadly divided into those which entertain or open up the space for dialogic alternatives and, alternatively, those which suppress or close down the space for such alternation.

The typology has emerged from continued research into the interpersonal functionality of discourse, research interested in how language construes social roles and relationships and in the potential of language to operate rhetorically to influence beliefs, attitudes, expectations and modes of interrelating. In order to demonstrate the application of the typology to the exploration of such questions, the paper singles out one issue for close attention - the linguistic mechanisms by which texts naturalise certain value positions and construct for themselves ideal, model or compliant readerships.

Keywords: modality; hedging; stance; dialogism; heteroglossia; engagement 


\section{Introduction}

My purpose in this article is to explore the resources of intersubjective stance. That is to say, I am interested in the communicative and rhetorical functionality of those wordings by which speakers/writers take a stance towards the various points-of-view and value positions being referenced by the text and thereby align themselves vis-à-vis those who hold, or are represented as holding, these positions. In this, I am at least in part responding to Stubbs's (1996) call for continuing work on what he terms the 'modal grammar of English', although my orientation is more semantic than 'grammatical'.

In the approach I set out here, these resources are seen to encompass a diverse array of lexico-grammatical forms and structures, wordings which are typically treated under such headings as modality, polarity, evidentiality, hedging, intensification, attribution, concession, and consequentiality. ${ }^{1}$ In operating with such a broad grouping, I draw inspiration from others who have had a similar semantic or rhetorical orientation. These include, for example, Martin $(1992,1997)$, whose category of ENGAGEMENT (as a cover-all term for resources of intersubjective positioning) I have taken over and seek to develop, and Stubbs (1996) who proposes that the category of 'modality' should be extended well beyond the modal verbs to include all wordings by which speakers/writers modulate their attachment to, or detachment from, the proposition. My approach is also broadly compatible with the 'meta-discourse' literature (e.g., Crismore 1989) where there is a similar grouping of a diverse array of wordings within a broad rhetorical category.

My interest in these wordings is a discourse semantic or rhetorical one and the approach I offer emerges from a concern with some of the long standing and ever challenging issues of discourse semantic analysis ${ }^{2}$ - for example, how it is that relations of status, power, social contact and solidarity are construed in text, by which patterns of lexico-grammatical choices are different types of authorial personae construed, and by what means do texts construct for themselves intended, ideal or model readerships? These wordings, of course, play a central role in the discursive accomplishment of such effects.

In this article I propose that in order to adequately describe and account for the communicative functionality of these resources, it is necessary to see them as fundamentally dialogic or interactive. That is to say, I am arguing that by the use of wordings such as perhaps, It has been argued that . . , naturally . . , admittedly, I think . . , the textual voice acts firstand-foremost to acknowledge, to engage with or to align itself with respect to positions which are in some way alternatives to that being advanced by the text. In this, of course, I rely on the now widely influential view of 
verbal communication as propounded by Bakhtin/Vološinov. ${ }^{3}$ For Bakhtin/ Vološinov, all verbal communication, whether written or spoken, is 'dialogic' in that to speak or write is always to refer to, or to take up in some way, what has been said/written before, and simultaneously to anticipate the responses of actual, potential or imagined readers/listeners. As Vološinov states:

The actual reality of language-speech is not the abstract system of linguistic forms, not the isolated monologic utterance, and not the psychological act of its implementation, but the social event of verbal interaction implemented in an utterance or utterances.

Thus, verbal interaction is the basic reality of language.

Dialogue ... can also be understood in a broader sense, meaning not only direct, face-to-face, vocalised verbal communication between persons, but also verbal communication of any type whatsoever. A book, i.e., a verbal performance in print, is also an element of verbal communication.... [it] inevitably orients itself with respect to previous performances in the same sphere... Thus the printed verbal performance engages, as it were, in ideological colloquy of a large scale: it responds to something, affirms something, anticipates possible responses and objections, seeks support, and so on. (Vološinov 1995: 139)

In this dialogic view of these resources, I stand apart from much of the modality and evidentiality literature (see for example, Lyons 1977; Palmer 1986 or Chafe and Nichols 1986) and at least some of the hedging literature (see Markkanen and Schröder 1997) where accounts of epistemic modals and similar resources, for example, often assume that the sole function of these wordings is to reveal the speaker/writer's state of mind or knowledge, to indicate that the speaker/writer is uncertain or tentative and is not committed to the truth value of the proposition. ${ }^{4}$

My purpose in this article, then, is to both justify my claims for the dialogic functionality of these resources and to demonstrate the types of insights this dialogic perspective can provide into the issues of rhetorical positioning outlined above. Accordingly, I provide a taxonomy of the various options by which intersubjective positions are adopted, with that taxonomy attending to how, and to what ends, the textual voice engages with alternative voices and positions and thereby actively represents the communicative context as one of heteroglossic diversity. I will use the term 'heteroglossic engagement' as a general label for these wordings. ${ }^{5}$ Naturally I will consider these various options individually, seeking to describe the specifics of their dialogic functionality. But I will also propose a more general axis of variation in rhetorical functionality by which, I will argue, it is possible to group the resources into two broad and opposed categories. Specifically I will propose that these resources can be classified as either 'dialogically 
expansive' or 'dialogically contractive'. Here I am attending to the degree to which an utterance, by dint of one or more of these wordings, entertains dialogically alternative positions and voices (dialogic expansion), or alternatively, acts to challenge, fend off or restrict the scope of such (dialogic contraction). Thus I will be proposing that all these resources can be analyzed as either dialogically expansive or dialogically contractive.

In order to demonstrate the application of this typology to the types of discourse analytical questions outlined above, I undertake some detailed analyses of two instances of journalistic commentary. Such mass-communicative texts (texts directed at a wide, generally unknown audience) enable me to explore questions relating to how the authors of such texts construe themselves as morally authoritative, how they naturalise certain value positions and how they represent themselves as aligned or dis-aligned with their intended or imagined readers.

\section{The monoglossic}

I begin with the broadest, most clear-cut distinction: between utterances which do engage with dialogic alternatives (heteroglossic engagement) and those which do not (heteroglossic disengagement). Consider the following opening paragraphs from an editorial in the British news and current affairs weekly, the Spectator.

(1) Extract: the Spectator

1 There are few sights more nauseating than that of a trade union leader trying to say, 'I told you so'.

2 When the news came through that the National Air Traffic Services (Nats) was in financial trouble and was being offered a $£ 60$ million rescue package,

3 the reaction of the first union official to pop up on the BBC's radar screen was predictable:

4 'I firmly believe that air traffic control and the safety of both passengers and those who live near and work in Britain's airports are far too important to be trusted to the vagaries of market forces or indeed shareholders interest.'

5 The preposterous idea that privatisation puts profit before safety was a commonplace long before Nats was born.

(editorial, the Spectator, 23/02/2002)

There are some obvious moments of dialogism in the extract as the textual voice, through quotation, engages with, and positions itself with respect to, 
the views of the 'first union official to pop up on the BBC's radar screen' and those of like mind. That quoted material is itself, in turn, dialogic in its use of the formulation 'I firmly believe', a point which will be taken up below. But my concern at this point is a narrower one. It is specifically with the way in which the author formulates the view that the anti-privatization position is 'preposterous' ('The preposterous idea that privatization puts profits before safety ...') and that those who advance this position are 'nauseous' ('There are few sights more nauseating than ...') and 'predictable' ('the reaction of the first union official ... was predictable ...'). The point here is that these derogatory and dismissive evaluations are introduced into the text via bare assertion. Accordingly these propositions are declared absolutely. There is no acknowledging of alternative positions with respect to these particular evaluations, no recognition that such propositions operate within a continuing debate. Rather, the text represents each of these negative evaluations as located in the textual voice's single, autonomous and isolated subjecthood, and as not in tension with, or contradistinction to, any alternative position or positions. Thus from the Bakhtinian perspective, such bare assertion is 'monoglossic' or 'undialogized' (Bakhtin 1935[1981]: 427).

What does this mean in terms of rhetorical or intersubjective positioning? Here we need to consider the contexts in which the bare assertion typically operates. Although much more corpus-based research is required into this area, we can say with reasonable certainty that the bare assertion is usually associated with consensual 'knowledge', versions-of-events which are seen as 'fact' - that is to say, with propositions held to be unproblematic and generally 'known' or 'accepted' in the current communicative context. Thus Myers (1990) observes of barely asserted ('unhedged') claims in scientific discourse that they are almost certainly 'not statements of new knowledge', but, rather, statements of 'facts' and established knowledge. Thus the bare assertion, the undialogized utterance, frequently (and perhaps typically) operates where there is an assumption of ontological, epistemic and axiological commonality between textual voice and audience, where the addressee is assumed to operate with the same knowledge, beliefs and values as those relied upon by the proposition. The undialogized bare utterance typically operates when this commonality is assumed not to be at risk or in doubt.

But evaluations of the type found in the Spectator extract are clearly not generally 'known', 'accepted' or taken as 'given'. Directed as they are against a relatively mainstream, relatively influential social position, there are obvious social contexts in which they would be hotly disputed. Even though here they are presented as dialogically inert, there would be many social contexts in which they would be dialogically active. In this, of course, the textual voice contrasts with the union official which the text 
itself quotes. Tellingly, the union official is represented, through his use of the formulation 'I firmly believe', as grounding his proposition in his own individual, contingent subjecthood and thereby representing his value position as but one among a potential diversity of viewpoints. The functionality of this type of formulation will be explored in more detail in later sections.

There is, as well, a more general issue relating to these propositions' status as evaluations which I must mention in passing. Other researchers interested in intersubjective positioning have demonstrated the importance of attending to the nature of the proposition. Thus, for example, various writers on the phrase I think have demonstrated the need to attend to whether the proposition is a 'fact' (a claim about some observable, verifiable state of affairs in the experiential world ) or some type of 'opinion' (see, for example, Stubbs 1996 or Simon-Vandenbergen 2000). They have shown that the meaning or rhetorical functionality of I think varies according to the nature of the proposition (i.e., 'fact' versus 'opinion') it modulates. Accordingly we take note here (beyond the specific negative assessment being advanced) that we are dealing with evaluative (rather than 'factual' propositions). And we note that certain potential rhetorical effects of intersubjective positioning arise firstly from the combination of bare assertion with evaluative proposition, and secondly from the combination of bare assertion with a specific type of evaluation (negative assessment directed at relatively influential social actors and a relatively widely-held value position.)

Under the first potential effect, the textual voice constructs itself as having the status and moral authority not only to pass an extremely negative judgment on a relatively popular, relatively influential viewpoint but also to pass judgment in a way which chooses not to recognize, and hence would suppress, alternative viewpoints. Thus this is the authority to both derogate and to ignore. I note, in passing, that those who hold the derogated position are not evaluated by reference to some purported shortcoming in their behavior (i.e., as being misguided or uninformed or lacking sound reasoning skills) but by reference to the negative emotional effect they are said to have on the author - they are 'nauseating'. ${ }^{6}$ Thus the author construes his own, individual emotional reactions as being of significance for the Spectator's mass audience.

Under the second potential rhetorical effect, the textual voice constructs for itself a particular relationship with its projected or modeled readership. As we saw, the bare assertion is frequently associated with an assumption that speaker/writer and audience operate with the same knowledge, beliefs and values. Accordingly, by such a formulation, the textual voice constructs itself as being in solidarity with a readership which holds the same antagonistic, contemptuous and dismissive view of the anti-privatization position and those that propound it. I note in this regard that the Spectator is a journal 
which defines itself as, and is widely recognized as, the mouthpiece and the standard bearer (to mix my metaphors) of British conservatism and the British Tory party. Such a positioning of the modeled reader, (this kind of assumption of solidarity), would appear to be consistent with this identity and political role, given that the British conservative position is one of strong support for privatization.

We see, then, that the combination of the monoglossic bare assertion (heteroglossic disengagement) with a strongly negative evaluation of this type has the potential to construct a particular authorial authoritativeness or at least assertiveness, and a particular relationship between author and readership. (In this case, the particular authorial persona construed is further nuanced by the sub-types of evaluation involved-here the choice of AFFECT rather than JUDGMENT in the opening evaluative move). Thus to employ a bare assertion in such a context, to adopt a stance of dialogic disengagement, is highly charged rhetorically. The bare assertion in this broad sense is 'modal' - it represents a particular intersubjective stand.

\section{Construing heteroglossic engagement: dialogic expansion and contraction}

At the broadest level, then, I make a two-way distinction between the monoglossic utterance (the undialogized bare assertion) and the heteroglossic or dialogistic utterance in which some engagement with alternative positions and/or voice is signalled. I turn now to a text which exemplifies most of the resources of heteroglossic engagement and provides for an interesting investigation of authorial personae and the construction of a model reading position. The text is extracted from a short comment piece contributed to the Courier-Mail newspaper (Brisbane, Australia). It was part of a debate about new laws the Queensland state government was proposing to introduce as a counter to perceived increases in racism. It was entitled, 'The Case Against'.

(2) Extract: the Courier-Mail

1 DOES Premier Peter Beattie want us to think what a fine anti-racist fellow he is?

2 Or does he want to advance the tolerance which is such an important characteristic of Australian society?

3 In the past few years there have been a number of moral panics about racism, accompanied by self-serving calls from predictable quarters for more government action to deal with the problem.

4 These panics are invariably based on questionable grounds. 
5 Either a few nasty statements or incidents are blown out of all proportion, or the definition of racism is expanded to cover a range of new sins.

6 In the wake of last week's revelations about the Ku Klux Klan's presence in the state, the Premier has stated that tougher anti-racial hatred laws are on the 'drawing board'.

7 But we already possess laws against threatening behaviour and incitement to violence.

8 New or tougher legislation is not going to solve the problem.

9 Indeed, if I were running an extremist organisation I would welcome such legislation as offering wonderful opportunities for publicity and martyrdom.

10 If we are really witnessing an increase in racial intolerance, as the Queensland Anti-Discrimination Commissioner and her comrades claim, perhaps it is time to ask whether the whole anti-racist apparatus that has grown up in the past couple of decades is counter-productive.

11 We have been asking the wrong questions.

12 What we should be considering is how post-World War II Australia managed to integrate millions of people from many backgrounds while retaining a degree of social and political harmony that is rare in today's world ....

13 I would contend that this enviable level of tolerance is not the result of direct government laws or interventions.

14 Although it sticks in the craw of the anti-racist industry to admit it, this tolerance is very largely the product of the cultural values and institutions and the historical experiences of the mainstream Australian population.

15 Beattie's Government should forget about new legislation and give careful consideration to Hastie's Law (named after the Englishman of their own political persuasion who formulated it).

16 'In any society racism will increase in direct proportion to the number of people who are given well-paid and prestigious positions to discover it.'

We note firstly that a number of key evaluations are monoglossically formulated - for example, propositions that the anti-racism 'industry' is self-serving, blows incidents out of all proportion and overextends the term 'racism'. I will return to the significance of such formulations in a later section. Against this, we note that at other rhetorically key points, the stance is heteroglossic - the text recognizes or engages alternative positions and voices. Tellingly, one such instance of dialogic engagement occurs at the text's opening: 
1 DOES Premier Peter Beattie want us to think what a fine anti-racist fellow he is?

2 Or does he want to advance the tolerance which is such an important characteristic of Australian society?

Questions in single-party, written texts (for which I will employ the traditional term 'rhetorical question' for ease of reference) can be seen as dialogic to the extent that they mimic interactive turn-taking as it typically operates in multi-party, ${ }^{7}$ spoken communication. But they can also be seen as dialogic for what I believe are more profound reasons. Pseudo or rhetorical questions of this type can perform at least two functions - (a) they can be used to introduce a proposition in such a way that it is presented as but one of a number of possible positions, ${ }^{8}$ or (b) they can operate to represent the proposition as so self-evident or agreed upon that it doesn't actually need to be stated by the textual voice, it can be left up to the reader to supply the required meaning. ${ }^{9}$ Consider the following by way of illustration of type a. (The question was part of a headline on the front page of the Guardian's G2 features section. The headline is superimposed over a full-page photograph of two men lying shot dead on a suburban footpath.)

(3) Type a

The man on the right topped the FBI's most wanted list. Does Ramon Arellano Felix's death spell the end for the world's deadliest drug cartel?

Here the proposition that this death will end the world's deadliest drug cartel is clearly introduced as simply a possibility, as a position which is worth considering but to which the writer is not committed. A similar meaning could have been conveyed by some modal of probability-for example, 'Perhaps/It's probable this man's death spells the end ...' Such a formulation is dialogic in the sense that the textual voice thereby actively indicates that alternative propositions are possible or even likely. The writer thus entertains these alternatives and thereby locates the current proposition in a context of heteroglossic diversity.

Rhetorical questions of the second type are exemplified by the following question from the front cover of the 25 March, 2002 edition of the New Statesman magazine. A full-page colored picture depicts a group of young, friendly and happy Iraqi children in close-up. Looking up towards the camera, they wave bunches of flowers and with welcoming smiles directly engage with the viewer. The text of a headline superimposed over the picture reads.

(4) Type b

Iraq: Should we go to war against these children? 
Here the question leads the reader to an 'obvious' answer. The reader is positioned to supply, 'No, of course we shouldn't go to war with these children'. Thus, the text is dialogic in that it represents the textual voice as taking up a 'common sense' viewpoint, the view of the reader. A dialogic exchange is enacted by which reader and writer are represented as concurring. But such formulations are heteroglossic in another dialogic direction, so to speak. In this instance, the proposition was in opposition to arguments emanating at the time from the United States government that war should be waged against Iraq. The functionality of this rhetorical question is thus very much one of challenging and attempting to defeat this alternative pro-war position. It is thus dialogic in that it acknowledges an alternative position while, at the same, seeking to head it off.

In the comparison of these two types of rhetorical question we see demonstrated one of the primary parameters by which heteroglossic engagement may vary. On the one hand there are those resources for construing engagement by which the textual voice is positioned as being open to, or entertaining, dialogic alternatives. That is to say, by these meanings, alternative positions are construed as possible or even likely and as to greater or lesser degrees authorized. I label this communicative effect 'dialogic expansion'. Type $a$ rhetorical questions belong to this grouping. On the other hand, there is another set of engagement resources which act to reject, counter, confront, head off or rule out actual or potential dialogic alternatives. Thus while still dialogic in that they acknowledge dialogic alternatives, they nevertheless act to close down or contract the space for these. They all act in some way to increase the interpersonal cost to those who would challenge the viewpoint currently being advanced by the text. I term this effect, 'dialogic contraction'. Type b rhetorical questions belong to this grouping.

We can say, therefore, that in contrast to extract (1), the opening of extract (2) is heteroglossic. By the use of this 'rhetorical' question form, the viewpoint being advanced by the text is represented as dialogically active rather than inert, as both contestable and contentious. But I have not yet settled whether this particular question is dialogically expansive or contractive. I will attempt to do so now.

\subsection{Dialogic contraction}

We are presented with a choice. Either the Australian Premier wants to advance tolerance or he wants us to think of him as a fine anti-racist fellow. (The second option, of course, implies the strongly negative evaluation that the Premier is only interested in his own popularity and political advancement.) As an Australian with some knowledge of Australian politics 
and popular opinion towards politicians, I read the text here as positioning me to supply the second option as answer, although I accept that this may not be so clearly felt by a reader without this background..$^{10}$ Thereby, at least from my reading position, the text represents the proposition that the Premier is self-interestedly motivated as commonsensical and unavoidable, as shared by writer and reader. From my reading position, then, this is an instance of dialogic contraction.

In this, the rhetorical question shares a functionality with a set of wordings which perhaps more obviously represent the textual voice as taking up some generally held position and thereby as concurring with the reader. This stance is typically conveyed by means of adverbials such as naturally, obviously and some uses of of course. For example:

(5) His idea was that an important ninth century bishop called John Anglicus may indeed have given birth to a child in full view of everyone on the streets of Rome, but that this bishop was not and never had been the pope. Of course, there is no evidence whatever for this, as Leibnitz himself well knew (Collins Bank of English).

I should mention in passing an additional rhetorical functionality which attaches to such expressions, a functionality related to the construal of writer-to-reader alignments, what I term 'dialogical alignment/disaligment'. By the use of a naturally or an of course, the textual voice actively and explicitly presents itself as aligned with the construed reader, as having the same belief or attitude or 'knowledge'. I will return to this particular mode of construing alignment in a later section.

This rhetorical question, then, falls within a grouping of dialogically contracting meanings which I label PROCLAMATION. Under PROCLAMATION, the textual voice conveys a heightened personal investment in the viewpoint being advanced and thereby explicitly indicates an interest in advancing that viewpoint, typically against some opposed alternativehence the term 'proclaim'.

The rhetorical question discussed above is an instance of one mode of PROCLAMATION, which I term CONCURRENCE. There are two other modes of PROCLAMATION, both of which operate in extract (2)-what I term PRONOUNCEMENT and ENDORSEMENT.

Under PRONOUNCEMENT, we are concerned with intensifications, authorial emphases or explicit authorial interventions or interpolations. ${ }^{11}$ By such, the textual voice conveys the heightened investment mentioned above and thereby confronts a contrary position. We see such a dialogic confrontation in sentence 13 of extract (2).

13 I would contend that this enviable level of tolerance is not the result of direct government laws or interventions. 
Here the textual voice's 'contending' is very much contra its dialogic opponents, contra any who would give credit to the 'anti-racism industry' for the 'enviable' level of tolerance.

PRONOUNCEMENTS involve the foregrounding in some way of the subjective involvement of the textual voice. They can be paired with what I term ENDORSEMENTS, formulations in which, similarly, there is a foregrounding of a textual voice, but in which the foregrounded subjecthood is that of some external source introduced into the text by attribution. For example:

(6) Follain punctures the romantic myth that the mafia started as Robin Hood-style groups of men protecting the poor. He shows that the mafia began in the nineteenth century as armed bands protecting the interests of the absentee landlords who owned most of Sicily. He also demonstrates how the mafia has forged links with Italy's ruling Christian Democrat party since the war (Collins Bank of English)

Here the meaning is not 'I' contend but, rather, 'I' plus 'some authoritative or otherwise convincing external source" contend. By the use of a reporting verb such as demonstrate or show, or by an evaluative formulations such as convincingly argued, compellingly propounded, successfully explained etc., the textual voice indicates its endorsement of the current viewpoint, indicates that it stands with the attributed source in advancing the current proposition. Such formulations are, of course, retrospectively dialogic in that they represent the textual voice as responding to, and taking up, what has been said/written previously by some other textual voice. But they can also be prospectively dialogic in that, as in the case of PRONOUNCEMENT, they can act to represent the textual voice as fending off or challenging actual or potential dialogic alternatives. In the example above, for example, the attributed source 'shows' the malign character of Mafia members, contra the popular view of them as 'Robin Hood' types. This fending-off effect is achieved as a consequence of the current viewpoint being (a) shared by both the textual voice and additional sources and (b) the purported authoritativeness of the cited external source.

In extract (2), the instance of ENDORSEMENT occurs in the conclusion. Beattie's Government should forget about new legislation and give careful consideration to Hastie's Law (named after the Englishman of their own political persuasion who formulated it.) 'In any society racism will increase in direct proportion to the number of people who are given well-paid and prestigious positions to discover it.' Here the author endorses the quoted proposition by indicating that it 'should be given careful consideration' and by noting that the source, Hastie, is of the same political party as those he is confronting. It is thereby, presumably, particularly credible and authoritative in the current context. 
Proclamations of these three types (CONCUR, PRONOUNCE and ENDORSE) are dialogically contractive in that, thereby, the textual voice puts on display its personal investment in the viewpoint being advanced and accordingly increases the interpersonal cost for any who would advance some dialogic alternative. They stand beside a second grouping of resources which are even more contractive in that they entail the direct rejection or countering of a dialogically contrary position. These are the resources which I group under the general heading of DISCLAMATION and which operate either as DENIAL (negation in the broadest sense) or as COUNTERING (various types of concessives, adversatives, and counter-expectancy).

The interactive or dialogic functionality of DENIAL (negation) has been widely discussed in the literature. ${ }^{12}$ Summarizing, we can say that the negative acts to invoke or activate the positive - that is to say, it sets the current utterance up as operating in some form of dialogic opposition to the positive alternative. ${ }^{13}$

Under the second disclaiming option, COUNTER (concession etc), it is some expected, rather than a directly negated, position which is disclaimed. Consider the following example from extract (2).

6 In the wake of last week's revelations about the Ku Klux Klan's presence in the state, the Premier has stated that tougher anti-racial hatred laws are on the 'drawing board'.

7 But we already possess laws against threatening behaviour and incitement to violence.

Here the counter-expectational 'but' in 7 represents the textual voice as countering an expectation which it presumes to have arisen in the current communicative context as a result of the Premier's announcement of plans for anti-racial hatred laws - namely the expectation that the state needs new legislation because it doesn't already possess laws for dealing with this type of threatening and violence inciting behavior. The expectation is ruled to be unfounded — such laws do already operate.

Additionally, we again see the action of dialogic alignment/disalignment as discussed in the previous section (in connection with wordings such as naturally and of course). Here the effect is more complex. On the one hand, the textual voice sets itself against those who feel new laws may be needed. On the other hand, this rejected viewpoint is represented, via the counter-expectancy, as generally held and hence held, presumably, by readers themselves. So the textual voice indicates dis-alignment with the construed readership in terms of whether or not new laws are required, yet, at the same time, via the counter-expectancy, characterizes this rejected viewpoint as to some degree understandable or even logical since it is shown to be based on a not unreasonable expectation. If the Premier announces 
such laws then surely it is reasonable to assume that they are needed. Thus the textual voice both aligns and dis-aligns - there is a counter effect by which the dis-alignment between textual voice and reader is mitigated.

There is, of course, an additional rhetorical twist at work here. The Premier is thereby represented either as being ignorant about his own laws or as having chosen to ignore their existence for some strategic political purpose.

As might be predicted, instances of both DENY and COUNTER occur throughout extract (2) as the writer sets himself against the view that new anti-racism laws are needed. Thus we find DENIALs in lines 8 and 13 and COUNTERS in lines 6, 7 and 14. I also interpret the really in line 10 as having some disclaiming functionality.

10 If we are really witnessing an increase in racial intolerance, as the Queensland Anti-Discrimination Commissioner and her comrades claim...

The 'claim' that there has been an increase in racism is thereby characterized as in some way doubtful, surprising, unexpected or otherwise untoward and is thus at least partially disclaimed. The resources of dialogic contraction are summarized in Table 1.

\subsection{Dialogic Expansion}

As discussed above, the resources of heteroglossic engagement can be broadly divided into the dialogically contractive (PROCLAIM and DISCLAIM)

Table 1. Summary of resources of dialogic contraction

Dialogic contraction

DisClaim

DENY: New or tougher legislation is not going to solve the problem.

COUNTER: The Premier has stated that tougher anti-racial hatred laws are on the 'drawing board'. But we already possess laws against threatening behaviour and incitement to violence.

Proclaim

CONCUR: $\quad$ The Premier, of course, wants us to think what a fine anti-racist fellow he is.

Pronounce: I would contend that this enviable level of tolerance is not the result of direct government laws or interventions.

ENDORSE: As Hastie (an Englishman of their own political persuasion) so compellingly argued, 'In any society racism will increase in direct proportion to the number of people who are given wellpaid and prestigious positions to discover it.' 
and the dialogically expansive. There are two primary modes of dialogic expansion, what I term ENTERTAIN and ATTRIBUTE. ${ }^{14}$ We find instances of both in line 10 in extract (2):

10a If we are really witnessing an increase in racial intolerance,

$10 \mathrm{~b}$ as the Queensland Anti-Discrimination Commissioner and her comrades claim,

10c perhaps it is time to ask whether the whole anti-racist apparatus that has grown up in the past couple of decades is counter-productive.

In line $10 \mathrm{a}$, the proposition that racial intolerance has increased is construed, via the use of the conditional, as being but a possibility, that is to say, as but one possible viewpoint in a diversity of possible viewpoints. (I have already explored how the positioning here is complicated by the presence of really.) The stance, then, is clearly dialogic as that textual voice is represented as entertaining alternative positions to that currently being referenced. We observe a similar stance towards the viewpoint in line 10c, namely the view that the anti-racist apparatus is counter-productive. Here we observe multiple layerings by which the textual voice represents itself as open to, or entertaining, alternative dialogic positions. Firstly the negative evaluation of the anti-racist apparatus is not simply proposed. Rather it is said to be a viewpoint which should be put up for consideration-'it is time to ask whether ... . Then the proposition that this question should be put is itself construed as but one possibility among other possibilities via the semantics of the modal adjunct perhaps. Thus the possibility that the question should not be put is acknowledged. ${ }^{15}$

In lines $10 \mathrm{a}$ and $10 \mathrm{~b}$, the proposition that racism is increasing is said to be 'claimed' by 'the Queensland Anti-Discrimination Commissioner and her comrades ('If we are really witnessing an increase in racial intolerance, as the Queensland Anti-Discrimination Commissioner and her comrades claim ...'). Thus the textual voice employs the resources of attribution/ reported speech to ground the viewpoint in the subjecthood of some external voice. As was the case with ENDORSE, such formulations are retrospectively dialogic in that they represent the textual voice as referencing the utterances of prior communicative participants. But they also have a prospective functionality. By attributing the viewpoint to the external voice, the author thereby represents it as contingent and individual, since it is explicitly grounded in the individual subjecthood of but one speaker. The viewpoint is therefore but one possible position, given the diversity of viewpoints which typically operate among different individual speakers. To attribute any given viewpoint in this way is to open up the dialogic space to alternative positions.

In line 10 in extract (2), however, the author has not simply attributed the viewpoint to an external speaker. He has employed one of a set of reporting 
Table 2. Summary of resources of dialogic expansion

Dialogic expansion

\begin{tabular}{ll}
\hline ENTERTAIN & $\begin{array}{l}\text { If we are really witnessing an increase in racial } \\
\text { intolerance; perhaps it is time to ask whether the whole } \\
\text { anti-racist apparatus that has grown up in the past couple } \\
\text { of decades is counter-productive. . . }\end{array}$ \\
ATTRIBUTE & the Premier has stated that tougher anti-racial hatred \\
ACKNOWLEDGE: & $\begin{array}{l}\text { laws are on the 'drawing board'. } \\
\text { the Queensland Anti-Discrimination Commissioner and } \\
\text { DISTANCE: }\end{array}$
\end{tabular}

verbs by which the textual voice can explicitly distance itself from the current viewpoint. ${ }^{16}$ In thereby casting some doubt on the proposition, such 'distancing' formulations even more thoroughly open up the dialogic space to alternatives. The resources of dialogic expansion are summarized in Table 2.

\subsection{JUSTIFICATION (modal consequentiality)}

I turn now to the final mode of heteroglossic engagement, a mode which, as we will see, plays a crucial role in the construal of a model or intended audience by extract (2). I am here concerned with formulations which construe a particular type of consequentiality, namely those by which non-'factual' propositions (for example, attitudinal evaluations, directives/ recommendation, predictions and so on) are justified, substantiated or otherwise argued for. When explicitly signaled in the text (and it is often left implicit), this relationship will typically be encoded through connectives and conjunctions such as therefore, thus, accordingly, because, for this reason, this is why. ${ }^{17}$ This is the sub-type of consequentiality which has been labeled 'epistemic' or 'internal-modal' (see Davies 1979; Sweetser 1990; and Verstraete 1998) and which would fall within the scope of what Halliday and Hasan (1976) and Martin (1992) term 'internal conjunction' and what rhetorical structure theory (Mann and Thompson 1993) terms JUSTIFICATION.

Such formulations are dialogic because, as Verstraete (1998: 201) observes, they represent the textual voice as taking an 'argumentative position'- they construct the textual voice as engaged in persuasion and some other communicative participant (typically the immediate addressee) as being in the role of 'persuadee', as holding a viewpoint which is to some extent different from that of the textual voice and against which the textual 
voice needs to mount an argument. There are a number of instances of such in extract (2). Consider, for example:

4 These [moral] panics are invariably based on questionable grounds.

5 Either a few nasty statements or incidents are blown out of all proportion, or the definition of racism is expanded to cover a range of new sins.

Here the evaluative proposition advanced in line 4 is provided with JUSTIFICATION, with argumentative support in line 5. Thus at least one element of the writer's negative position with respect to the anti-racism industry is represented as needing to be substantiated, and the audience as needing to be won over.

Having established this typology of resources of constructing intersubjective stance, I turn now to the question of the types of insights such a framework can supply into the discourse semantic issues I outlined in the opening.

\section{Applying the typology: The construed reader}

By way of demonstration, I return to extract (2) and the question of what has variously been termed the 'ideal', 'intended', 'imagined' or 'model reader' (for example, Eco 1984: 7-10 and Coulthard 1994: 4-5). Following Eco (1984), I see texts as construing or modeling readers by means of the assumptions they can be observed to make about the reader's knowledge, beliefs, values and expectations, and by means of the inferences and interpretations they rely on for their own internal logic or coherence. For the current purpose, I will focus primarily on one key issue, the issue of conformity or non-conformity with the author's viewpoint. To what extent is the reader modeled as sharing the author's beliefs, attitudes and opinions? I will also attend, where appropriate, to reader positioning which operates at the metadiscursive level. Here we are concerned with contexts where the modeled reader is either construed as dissenting from the way a text is formulated, from its mode of expression or, alternatively, is represented by the text's rhetorical terms as consenting to the current mode of expression.

By applying the typology of modes of intersubjective positioning set out above, it becomes possible to analyze a text's construction of its intended or imagined readership as a set of micro-maneuvers by which different alignments or affiliations are envisaged with an array of different value positions. As a consequence, it becomes possible to see imagined audience construal not in terms of some single modeled reader or reading position but, rather, in terms of multiple, not necessarily consistent readers or reading positions. 
The methodology I employ is to observe which value positions are referenced by the text and then to observe patterns of use of the resources of intersubjective stance with respect to these various positions. Thus in extract (2), we observe that, at a more delicate level of analysis, there are a number of value positions put at risk - for example, one which turns on attitudes towards the state's anti-racism institutions, one which turns on attitudes towards the Premier, and one which turns on the perception that racism is increasing and that legislative action is needed to counter this. My method, then, is to consider the text's treatment of these various positions, attending especially to any differences in intersubjective stance. I will discuss the treatment of each of these value positions in turn.

\subsection{The anti-racism 'industry'}

As briefly discussed above, the negative evaluation of the members of the so-called anti-racism industry is largely monoglossic. Thus bare assertions are used as they are pejoratively referred to as an 'industry' and as 'comrades', as they are condemned in the strongest terms. We find, for example, the following barely asserted evaluations of those working in the anti-racism sector (evaluative elements directed against the sector have been underlined).

3 [there have been] self-serving calls from predictable quarters ...

$5 \quad$... a few nasty statements or incidents are blown out of all proportion $\ldots$

5 ... the definition of racism is expanded to cover a range of new sins.

$14 \ldots$ it sticks in their craw to admit it ...

Thus the positioning with respect to this grouping is similar to that which operates in extract (1) in its derogation of the anti-privatization viewpoint. As we saw previously, by the use of the undialogized bare assertion (the mode typically associated with consensual 'knowledge') the proposition is represented as self-evident, agreed upon or otherwise dialogically unproblematic. The readership is modeled as not only uniformly sharing the author's view of the anti-racism 'industry', but also as acceding to the writer's representation of this position as a 'given', as dialogically inert. There is thus a strong assumption of solidarity at work here by which the reader is construed as standing with the writer against these pernicious, duplicitous ethnic-affairs bureaucrats.

There is, however, one interesting exception to this tendency, the instance of dialogic expansiveness associated with the author's proposition that this 
sector has, in fact, increased rather than decreased racism (it has been 'counter-productive'). As we saw, for this proposition the author employs the dialogically expansive resources of ENTERTAIN to actively open up the dialogic space to alternatives ('perhaps it is time to ask whether the whole anti-racist apparatus . . . is counter-productive'). By the use of this questioning formulation, the textual voice authorizes or at least recognizes a viewpoint which is contrary to its own. The modeled readership is thereby construed as potentially more diverse in its viewpoints, as potentially in disagreement with the textual voice. The use of the 'perhaps' has an effect on the meta-discursive level. The textual voice thereby represents itself as open to alternative positions on whether or not the question should be put, that is to say, on how the argumentation should be formulated as text. The readership modeling thereby recognizes and legitimates those who might resist this question being asked.

Reader modeling, then, for attitudes towards the 'anti-racism industry' is not entirely consistent. This reader is construed as, in most instances, in conformity with the author both attitudinally and meta-discursively, with just the one moment where alternative viewpoints are recognized and hence authorized.

\subsection{The Premier}

By the rhetorical question which begins extract (2) (as an instance of PROCLAIM/CONCUR - 'Does Premier Peter Beattie want us to think what a fine anti-racist fellow he is? Or does he ...'), the author not only establishes a solidarity position which is strongly negative towards the Premier, but also represents this negative view as generally agreed upon and 'commonsensical', as a view shared by both reader and writer. It is possible, therefore, to identify a clear authorial assumption that the reader will view the Premier in these terms. We do note that via the particular question form adopted here (the reader apparently invited to choose between a positively evaluative and a negatively evaluative option), there is a recognition of the dialogic contentiousness of the accusation directed against the Premier. The writer, after all, decided not to baldly assert that the Premier was cynically exploiting unfounded fears about racism to advance his own political career. Yet as discussed above, such formulations contract the space for any dialogic alternative, and here the space for a position less critical of the Premier is extremely minimal. Accordingly any readers who might dissent from this view are constructed as very much in the minority, as 'on the outer', so to speak, as at odds with the solidarity affiliation constructed for the modeled reader. 
Further interesting consequences for reader modeling arise from lines 6 and 7 in extract (1):

6 ... the Premier has stated that tougher anti-racial hatred laws are on the 'drawing board'.

7 But we already possess laws against threatening behaviour and incitement to violence.

As discussed previously, this may give rise to the inference that the Premier is either ignorant of, or is wilfully ignoring, the existence of anti-incitement to violence legislation. If the inference is, in fact, taken up by the reader, then the formulation has the effect of not directly asserting a negative evaluation of the Premier, but rather of assuming or presupposing one. It could be argued that this type of assumption is even more thoroughgoing in its exclusion of dialogic alternatives than the bare assertion (more monoglossic) since the proposition which is at stake has not been explicitly articulated and therefore is not so easily accessible to direct dialogic challenge. Accordingly, it may construe a model reader for whom the proposition is unavoidable, for whom it self-evidently arises through commonsensical deduction. But against this is the status of the proposition as inference. As such, it may be avoidable by the reader and hence these modeling effects would not ensue.

The reader modeling, then, for attitudes towards the Premier is to some degree open-ended or at least more open to variable interpretation, although the general tendency is clearly to model a reader who holds the same views as the author and who is untroubled by the terms in which these views are formulated.

\subsection{The proposed new laws}

Finally there is the reader modeling with respect to the perception that new laws may be needed to counter increases in racism. The text purports to mount a case against this position for the benefit of a general readership (hence its title, 'The Case Against'). To the extent that it does this, it presumably models a readership which includes at least some who hold to this countered position. We find explicit indicators that the text is, in fact, formulated in this way.

In line 11 in extract (2), the textual voice addresses a 'we' who is said to have been 'asking the wrong questions', presumably in assuming racism has been increasing and hence wondering whether new laws might be required. Similarly, in line 12 in extract (2) this 'we' is told that it should 'be considering how post-World War II Australia has managed to retain . . . a 
degree of social and political harmony that is rare in today's world'. By implication, then, the considerations of this 'we' have hitherto been misdirected. By this a reader is modeled whom the author challenges and corrects and who is thereby construed as somewhat at odds with the viewpoint being advanced by the text. Interestingly, the author aligns himself dialogically with this construed reader by his use of the inclusive pronoun, 'we', even while acting to put this reader straight.

This relationship of argumentative engagement is perhaps most explicitly indicated by those stretches which provide for justification/substantiation (epistemic consequentiality) of key propositions. Picking up from the earlier discussion we observe the following relations of substantiation (the initial proposition is presented first and the substantiation in the parentheses following).

1 These panics (claims of increases in racism) are 'based on questionable grounds' (because a few incidents are blown out of all proportion ...)

2 New legislation is not going to solve the problem (because extremist organisations will exploit it for their own ends)

3 Beattie's Government should forget about new legislation (because Hastie, an Englishman of their own political persuasion, has observed, 'In any society racism will increase in direct proportion to the number of people who are given well-paid and prestigious positions to discover it.')

4 We have been asking the wrong questions (because what we should be considering is how post-World War II Australia managed to integrate millions of people from many backgrounds while retaining a degree of social and political harmony that is rare in today's world.)

We note that lines 1-3 all argue contra the concern that racism is increasing and therefore new laws may be required. It is plausible to interpret such formulations as targeting at least some element of the construed audience, those conceived of as needing persuading or at least as standing to benefit from the clear articulation of the evidence upon which the author's position relies. We see this unambiguously in line 4 . Here the author directly engages with the construed reader ('we') and provides argumentation why 'we' have been on the wrong track. Thus through this implied relationship of persuader/persuadee the textual voice recognizes, and represents itself as dialogically engaged with, an alternative viewpoint.

We see therefore, that the reader modeling for this central proposition is significantly different from that for the viewpoint re the Premier and re the anti-racism 'industry'. Here, in contrast, agreement is definitely not assumed, in fact the opposite - a value position is modeled for the reader which is at odds with that of the textual voice. Tellingly, of course, this 
modeled difference of viewpoint is not in any way open. Its scope and focus are clearly defined by the processes of modeling I have described above-it is limited to just the one value position. And it operates, of course, against a background in which axiological unanimity (e.g., re the 'anti-racism industry') is unambiguously indicated.

\section{Conclusions}

The account of the resources of heteroglossic engagement I have provided here has, of necessity, been a partial one. The typology of resources I have set out attends only to the broadest, least fine-grained differences in rhetorical functionality. Thus I have not attempted to explore distinctions which might operate within, for example, PRONOUNCE, ENTERTAIN or CONCUR, which might operate between, for example, PRONOUNCEMENTS such as $I$ contend ... and the truth of the matter is that ..., or between instances of ENTERTAIN such as I believe, I think, perhaps, it seems, it seems to me and so on. Nevertheless, I hope that I have been able to demonstrate the fundamental dialogism of the various resources under consideration, that I have been able to demonstrate that for the writer/speaker to take a stance in these various ways (to modalize in the broadest sense of the word) is to construe the communicative context as heteroglossically diverse and to engage in different ways with that diversity.

Several key consequences flow from this account for the terms in which in we construe some of the key questions of linguistic analysis. This focus on dialogistic functionality leads compellingly to the conclusion that, in formulating categories for linguistic analyses of this type, we must look beyond commonalities in lexico-grammatical structuring or affordance and consider commonalities in rhetorical effect. To develop semantic accounts of this type it is necessary to acknowledge that the discursive realization of such intersubjective relationships involves wordings which may be lexico-grammatically diverse and disparate. The account also provides strong support for the view that stance and attitude are fundamentally social rather than personal, that when speakers/writers take a stand, when they construct for themselves a particular persona or identity, it is via a process of engaging with socially-determined value positions. The stances associated with a particular discursively construed identity are stances which operate interactively, which reference the value positions currently operating in society. And following from this, we are led to take a rather different view of what is at stake communicatively in the use of so-called epistemic modals and related resources. We no longer see truth-value as the primary motivation. Rather we see modality as a semantics by which the textual 
voice maps out its relationships with the various value positions brought into communicative play by the text.

\section{Notes}

1. For modality, see, for example, Lyons (1977), Palmer (1986) or Coates (1983); for evidentiality see Chafe and Nichols (1986); for hedging and/or boosting see Jakobson (1957), Myers (1989), Markkanen and Schröder (1997), Meyer (1997) or Hyland (1996).

2. I use 'rhetorical' in the broadest sense to refer to the potential of discourse to shape or influence beliefs about the world, attitudes, expectations and modes of inter-relating.

3. A debate continues, of course, as to whether the texts attributed to Vološinov were, in fact, authored by Bakhtin. See, for example, Dentith (1995).

4. For an alternative, more dialogic perspective within the hedging literature, see Myers (1989).

5. I take the term engagement from Analysing Genre: Functional Parameters, Martin (1997).

6. In terms of the APPRAISAL framework of Martin, White, Rothery, Iedema and Feez (Iedema et al. 1994; Martin 2000; White 1998; Rothery and Stenglin 2000), they are evaluated here by reference to AFFECT (emotional reaction) rather than by reference to JUDGMENT (positive and negative assessments of human behavior by reference to some system of social norms).

7. The term 'rhetorical question' is employed variously in the literature. It is sometimes used very generally as a label for questions which are seen as not genuinely seeking new information and sometimes more narrowly for those questions which activate assertions of the opposite polarity to the question. See, for example, Sadock (1974). I use the term here in the broader sense.

8. Questions of this type are sometimes termed 'expository questions'-see, for example, Goatly (2000: 89).

9. These are rhetorical questions in the narrower sense of the term - for example, Sadock (1974).

10. I am indebted to Anne-Marie Simon-Vandenbergen (personal communication) for some very useful insights into the rhetorical effects of this formulation for a non-Australian readership.

11. For example, I contend..., The facts of the matter are that ..., The truth of the matter is that..., We can only conclude that..., You must agree that ..., intensifiers with clausal scope such as really, indeed etc and appropriately placed stress (e.g., 'The level of tolerance $i s$ the result of government intervention').

12. See, for example, Pagano (1994) or Leech (1983: 101). For a discussion of the rhetorical exploitation of this potential see Fairclough (1989: 152, 1992: 121).

13. Thus Leech states, 'In fact, the [Co-operative Principle] will predict that negative sentences tend to be used precisely in situations when ... [the speaker] wants to deny some proposition which has been put forward or entertained by someone in the context (probably the addressee) (1983: 101).

14. I am indebted to Jim Martin (personal communication) for a number of these labels.

15. The category of ENTERTAIN includes modals of probability/epistemic modality (e.g., perhaps, probably, he may be corrupt, he must be corrupt etc.) and related wordings 
(e.g. in my view, I suspect, I think, etc.), evidentials (e.g., it seems, apparently, the evidence suggests ... etc.) and hearsay (I hear).

16. This particular distancing functionality has been quite widely explored in the literature. See, for example, Caldas-Coulthard (1994).

17. I rely here on Martin's account (1992: 183) of how conjunctive relations can operate implicitly between sentences/clause-complexes. I am also influenced here by Hoey's framework by which texts are analysed by reference to whether the EVALUATIONs advanced are supported by what Hoey terms a 'basis' 8 (Hoey 2000).

\section{References}

Bakhtin, M. M. (1935 [1981]). The Dialogic Imagination: Four Essay. Edited by M. Holquist, translated by C. Emerson and M. Holquist. Austin: University of Texas Press.

Caldas-Coulthard, C. R. (1994). On reporting reporting: The representation of speech in factual and factional narratives. In Advances in Written Text Analysis, Coulthard, M. (ed.), 295-309. London/New York: Routledge.

Chafe, W. L. and J. Nichols, (eds.) (1986). Evidentiality: The Linguistic Coding of Epistemology, Norwood, NJ: Ablex.

Coates, J. (1983). The Semantics of Modal Auxiliaries, London/Canberra: Croom Helm.

Coulthard, M. (1994). On Analysing and Evaluating Text. In Advances in Written Text Analysis, Coulthard, M. (ed.), 1-11. London: Routledge.

Crismore, A. (1989). Talking With Readers: Metadiscourse As Rhetorical Act (American university studies series XIV : Education). New York: Peter Lang Publishing.

Davies, E. (1979). On the Semantics of Syntax: Mood and Condition in English. London: Croom Helm.

Dentith, S. (1995). Bakhtinian Thought. London/New York: Routledge.

Eco, U. (1984). The Role of the Reader. Explorations in the Semiotics of Texts. Bloomington, IN: Indiana University Press.

Fairclough, N. (1989). Language and Power. London: Longman.

- 1992. Discourse and Social Change. Cambridge: Polity Press.

Goatly, A. (2000). Critical Reading and Writing-An Introductory Coursebook, London/ New York: Routledge

Halliday, M. A. K. and Hasan, R. (1976). Cohesion in English. London: Longman.

Hoey, M. (2000). Persuasive rhetoric in linguistics: A stylistic study of some features of the language of Noam Chomsky. In Evaluation in Text: Authorial Stance and the Construction of Discourse. Hunston, S. and G. Thompson, (eds.), 28-38. Oxford: Oxford University Press.

Hyland, K. (1996). Writing without conviction: Hedging in science research articles, Applied Linguistics 17 (4): 433-54.

Iedema, R., Feez, S. and White, P. R. R. (1994). Media Literacy. ('Write it Right' Literacy in Industry Research Project-stage 3) Sydney: Metropolitan East Disadvantaged Schools Program, NSW Department of School Education.

Jakobson, R. (1957). Shifters, Verbal Categories and the Russian Verb (Russian Language Project). Harvard University: Department of Slavic Languages and Literature.

Leech, G. (1983). The Principles of Pragmatics. London/New York: Longman.

Lyons, J. (1977). Semantics. Cambridge: Cambridge University Press.

Mann, W. C. and Thompson, S. A. (1993). Rhetorical structure theory: A theory of text organisation and its implications for clause combining. In Discourse Structure, L. Polyani (ed.). Norwood, NJ: Ablex. 
Markkanen, R. and Schröder, H. (eds.) (1997). Hedging and Discourse: Approaches to the Analysis of a Pragmatic Phenomenon in Academic Texts. Berlin/New York: Walter de Gruyter.

Martin, J. R. (1992). English Text, System and Structure, Philadelphia/Amsterdam: John Benjamins.

-(1997). Analysing Genre: Functional Parameters.In Genres and Institutions: Social Processes in the Workplace and School, Christie, F. and J. R. Martin (eds.), 3-39. London, Cassell.

- (2000). Beyond Exchange: ApPraisal Systems in English. In Evaluation in Text: Authorial Stance and the Construction of Discourse, S. Hunston, and G. Thompson, G. (eds), 142-175. Oxford: Oxford University Press.

Meyer, P. G. (1997). Hedging strategies in written academic discourse: Strengthening the argument by weakening the claim. In Hedging and Discourse: Approaches to the Analysis of a Pragmatic Phenomenon in Academic Texts, R. Markkannen and H. Schröder (eds.), 21-42. Berlin/New York: Walter de Gruyter.

Myers, G.(1989). The pragmatics of politeness in scientific articles. Applied Linguistics 10: $1-35$.

-(1990). Writing Biology: Texts in the Social Construction of Scientific Knowledge. Wisconsin, WI: University of Wisconsin.

Pagano, A. (1994). Negatives in written text. In Advances in Written Text Analysis, M. Coulthard (ed.), 250-265. London: Routledge.

Palmer, F. R. (1986). Mood and Modality. Cambridge: Cambridge University Press.

Rothery, J. and Stenglin, M. (2000). Interpreting literature: The role of APPRAISAL. In Researching Language in Schools and Functional Linguistic Perspective, L. Unsworth (ed.), 112-136. London: Cassell.

Sadock, J. M. (1974). Toward a Linguistic Theory of Speech Acts. New York/London: Academic Press.

Simon-Vandenbergen, A.-M. (2000). The function of I think in political discourse. International Journal of Applied Linguistics 10 (1): 41-63.

Stubbs, M. (1996). Towards a modal grammar of English: A matter of prolonged fieldwork. In Text and Corpus Analysis, 196-228. Oxford: Blackwell.

Sweetser, E. (1990). From Etymology to Pragmatics: Metaphorical and Cultural Aspects of Semantic Structure. Cambridge: Cambridge University Press.

Verstraete, J.-C. (1998). A semiotic model for the description of levels in conjunction: External, internal-modal and internal-speech functional. Functions of Language 5 (2): $179-211$.

Vološinov, V. N. (1995). Marixism and the Philosophy of Language. Translated by L Matjka and I. R. Titunik. London: Routledge.

White, P. R. R. (1998). Telling Media Tales: The News Story As Rhetoric. Sydney: University of Sydney.

- (2000). Dialogue and inter-subjectivity: Reinterpreting the semantics of modality and hedging. In Working With Dialog, M. Coulthard. J. Cotterill and F. Rock (eds.), 67-80. Tübingen: Max Niemeyer Verlag.

- (2002). Appraisal: The language of attitudinal evaluation and intersubjective stance. Appraisal website. URL. <www.grammatics.com/appraisal>.

Peter R. R. White lectures in linguistics and English language studies at the University of Birmingham. His key research interests include the language of evaluation and intersubjective stance, journalistic discourse across cultures, the discourses of popularization, argumentation, and academic literacy, and new developments in Systemic Functional Linguistics. He has published articles and journal articles on news reporting and news 


\section{P.R. R. White}

commentary, the language of science and technology, museum exhibitions as multi-modal texts and the language of evaluation and stance. He manages a website and email list concerned with the language of attitude and stance at <www.grammatics.com/appraisal $>$. $\mathrm{He}$ is co-authoring a book with James R. Martin on the APPRAISAL framework to by published by Palgrave in 2003. Previously, he worked as reporter and editor for newspapers and radio stations in Australia, and as a journalism trainer for Australia's Special Broadcasting Service. Address for correspondence: Dr Peter R. R. White, Department of English, University of Birmingham, Birmingham, UK B152TT <p.r.white@bham.ac.uk> and <prrwhite@btinternet.com>. 